\title{
Seguridad alimentaria. Kukra Hill-Región Autónoma Costa Caribe Sur-Nicaragua. 2016
}

\author{
Alice Marie Pineda Whitaker ${ }^{1}$ \\ Manuel E. Pedroza Pacheco ${ }^{2}$
}

\section{RESUMEN}

El presente estudio tiene como objetivo conocer la situación de la Seguridad Alimentaria Nutricional, en las familias del municipio de Kukra Hill-Región Autónoma Costa Caribe Sur (RACCS). Es una parte de la tesis de grado donde tengo resultados preliminares, utilizando la técnica cualitativa que es: Entrevistas a profundidad, con productores y mujeres amas de casa, del casco semi-urbano y rural. A estos se aplicaron 13 preguntas semi-estructuradas de SAN. Se entrevistaron a algunos actores sociales del municipio, aplicándoles cinco preguntas abiertas. Entre los principales resultados tenemos: Los actores sociales del municipio limitan el concepto de seguridad Alimentaria Nutricional a la Inocuidad y disponibilidad de los alimentos, y la propuesta de intervención para garantizarla va en ese mismo sentido. Las familias están vendiendo sus tierras a trasnacionales y colonos que llegan del pacifico, y los que no lo venden están cultivando los productos que la trasnacional define, para venderles el fruto. Muchos migran después de la venta de sus tierras a otros municipios de la RACCS, y a otros países como Costa Rica, Panamá, Estados Unidos. La disponibilidad de alimentos se ve afectado por: el tipo de productos que están cultivando y no aporta a la alimentación de las familias, la falta de tierra, el cambio climático y la proliferación de plagas. Hay Inseguridad alimentaria a nivel del hogar, y a nivel de la comunidad. Existe apoyo solidario entre la gente en la comunidad, y apoyo del gobierno a algunas familias y algunos productores. Los monocultivos están dominando el uso del suelo en el municipio, y los productos que son garantes de la Seguridad alimentaria como arroz, frijoles y maíz, están siendo importados.

Palabras Claves: Seguridad Alimentaria, Productores, Mujeres, Actores Sociales, Migración, monocultivo.

Recibido: 21 de octubre de 2016

Aceptado: 15 de noviembre de 2016

1 Doctorante en Desarrollo Rural Sustentable. UNAN-Maangua. Correo electrónico: a_alicia64@yahoo.com.

2 Co-Autor del articulo. Docente UNAN-Maangua. Correo electrónico: hppedroza@gmail.com 


\title{
Food safety in Kukra Hill, Autonomous Region, South Caribbean Coast, Nicaragua. 2016
}

\begin{abstract}
This study aims to determine the status of the Food Safety and Nutrition, families in Kukra HillAutonomous Region, South Caribbean Coast (RACCS). It is a part of my doctoral thesis which I have preliminary results, using the qualitative technique that is depth interviews. We interviewed house wives in semi-urban area and rural areas, producers of semi-urban area and rural areas were also interviewed. These 13 semi-structured questions of food safety applied. We interviewed some social actors in the municipality; these actors were asked five open questions. The main results are: The social partners of the municipality limits the concept of Food Security and Nutrition Safety, to food availability, and the proposed intervention to ensure it, goes in the same direction. Families are selling their land to settlers arriving, transnationals and people from the Pacific of Nicaragua, and those who do not sell their lands, are producing what the transnational define, and the product is commercialized with them. Many migrated after selling their lands and they move to other countries such as Costa Rica, Panama, United States. Internally they go to other municipalities in the RACCS. Food availability is affected by the type of products that are growing and does not contribute to feeding families, lack of land, climate change and the proliferation of pests. There is food insecurity at household and community level. There is support and solidarity among people in the community and government support for some families and some producers. Monocultures are dominating land use in the municipality, and products that are guarantors of food safety as rice, beans and corn, are being imported.
\end{abstract}

Keywords: Food Safety, Producers, Women, Social Actors, Migration, monoculture 


\section{INTRODUCCIÓN}

Para la FAO, la Seguridad Alimentaria (SAN) significa que todas las personas tengan acceso en todo momento a los alimentos que necesitan para desarrollar una vida sana y activa en condiciones dignas. Las estrategias planteadas son: aumentar la producción, generar empleo e ingresos y asistencia para facilitar el acceso de la población a los alimentos". (Cumbre Mundial sobre la Alimentación 1996).

"La seguridad alimentaria y nutricional se logra cuando todas las personas, en todo momento, disponen de alimentos adecuados (en términos de cantidad, calidad, inocuidad y aceptabilidad sociocultural), tienen acceso a ellos y los utilizan satisfactoriamente para llevar una vida sana y activa." (UNICEF 2008).

Nicaragua a pesar del gran potencial productivo, es el segundo país más pobre en América Latina, entre los principales problemas que enfrenta la población son: La pobreza es uno de los principales problemas que enfrenta la sociedad nicaragüense, reflejado en el 79.9\% de la población que sobrevive con dos dólares diarios y un $45.1 \%$ con un dólar al día (pobreza extrema), datos del Banco Mundial. Esto es inaceptable desde todo punto de vista. En el 2003 más de 800,000 personas no tenían acceso a la Canasta Básica de Alimentos (CBA). 1 El estado de la Inseguridad alimentaria en el mundo 2001. Según la Encuesta de Medición de Nivel de Vida 2014, del Instituto Nacional de Información de Desarrollo, para el período 2009 a 2014 en Nicaragua hubo una disminución de 13 puntos porcentuales en la pobreza nacional, que descendió de 42.5 a 29.6 por ciento. Mientras que, para el mismo período, la pobreza extrema presentó una disminución de 6 puntos porcentuales, tras pasar del 14.6 por ciento a un 8.3 por ciento. A pesar del progreso, la pobreza sigue siendo alta. Además, Nicaragua aún es uno de los países menos desarrollados de América Latina, donde el acceso a los servicios básicos. (INIDE 2014).
Estudios efectuados en Centroamérica han documentado la existencia de un círculo vicioso que tiende a perpetuarse de generación en generación: las madres que sufren desnutrición proteínico-energética y de micronutrientes, y mayor carga de infecciones, tienen hijos con bajo peso al nacer y corta edad gestacional que, si sobreviven, sufren múltiples infecciones y crecen y se desarrollan inadecuadamente. Cuando alcanzan la edad escolar tienen limitaciones en su rendimiento escolar, y durante su adolescencia y edad adulta muestran manifestaciones de desnutrición tales como: salud reproductiva alterada, baja productividad y bajo cociente intelectual. (INCAP 2004).

Las Metas de Desarrollo del Milenio centran la atención mundial en eliminar la pobreza extrema en sus diversas manifestaciones como el ingreso y hambre (objetivo 1), la educación (objetivo 2) y salud (objetivos 4, 5 y 6) en un marco de igualdad de oportunidades de género (objetivo 3), de desarrollo ambientalmente sostenible (objetivo 7) y fomentando una asociación mundial para el desarrollo (objetivo 8). (UNDP 2000).

La Cumbre de Presidentes de Centro América definieron los pilares de la Seguridad Alimentaria Nutricional. (SICA (2002), como:

- Disponibilidad: La disponibilidad de los alimentos es el aspecto más básico a considerar a nivel regional, nacional, local comunitario, familiar e individual. Sólo puede aseverarse que existe seguridad en cuanto a disponibilidad de alimentos a nivel nacional si los recursos alimentarios son suficientes para proporcionar una dieta adecuada a cada persona en ese país, independientemente de la procedencia de ese alimento, es decir, si es producido localmente o proviene de importaciones o donaciones. Se refiere a la cantidad y variedad de alimentos con que cuenta un país, región, comunidad o individuo. Esto dependerá de la producción, importación, exportación, transporte y medios de conservación de alimentos. Estrategias 
de sobrevivencia utilizadas por individuos $\mathrm{y}$ familias de agricultores que no producen suficientes alimentos para cubrir sus necesidades les permiten mantener ese balance.

Entre las medidas frecuentemente utilizadas se incluye la frugalidad, la utilización de las reservas de alimentos generalmente conservados con considerables pérdidas post-cosecha, el trueque, los cambios en la distribución intrafamiliar de alimentos, el reemplazo de fuentes de alimentos en la dieta tradicional, la venta de bienes, la reducción de la actividad física, la migración estacional de adultos y adolescentes.

- El acceso: La capacidad adquisitiva, determinada por la relación entre ingreso económico per cápita y familiar y el costo de los alimentos, se manifiesta a través del consumo de alimentos, el cual se refiere al "gasto" total realizado por los individuos, los hogares o por el país en bienes y alimentos en un período determinado. Los alimentos pueden estar disponibles en la comunidad y puede existir también la decisión de consumirlos, pero a la vez hay factores que los hacen inaccesibles siendo estos el ingreso, y el precio de los alimentos. El ingreso que está sujeto a un empleo, salario y educación.

- Consumo: está influenciado por la Cultura y hábitos alimentarios que comprende los conocimientos, creencias, arte, normas morales, leyes, costumbres y cualquier otra capacidad y hábitos adquiridos por el hombre como miembro de una sociedad. Es el fundamento a muchos valores, creencias y acciones del consumidor con relación a su alimentación; la cultura tiene un gran peso en definir qué es lo que se come, dónde y cómo. Por ejemplo, comidas típicas, preferencia o rechazo a ciertos alimentos, tabúes, tradición, religión, prestigio social, clasificación de alimentos fríos o calientes, etc. que influyen directamente en la selección y consumo de alimentos. Sin embargo, esta depende de: que haya alimento, que tenga como conseguir el alimento, conocimiento que tiene del alimento, estado de ánimo.

- Utilización biológica: Se refiere a las condiciones en que se encuentra el cuerpo, que le permiten utilizar al máximo todas las sustancias nutritivas que está consumiendo. Esto dependerá del estado de salud de la persona, lo cual es determinado, entre otros factores, por la higiene personal y de los alimentos o inocuidad, saneamiento del medio y agua potable y por la atención que brindan los servicios de salud. Está condicionado por el estado de salud, la forma de preparar los alimentos, hábitos higiénicos, inocuidad de los alimentos y condiciones del medio ambiente.

\section{MATERIALES Y MÉTODOS}

El presente estudio es analítico, con un enfoque cualicuantitativo. El universo de estudio fueron productores, amas de casa y actores sociales del municipio, ubicados en el área semi-urbana y rural. Un total de 41 personas entrevistadas.

Para la entrevista de productores y mujeres amas de casa, se elaboró un cuestionario con 13 preguntas semi-estructuradas. Las preguntas se basaron en: la alimentación, de donde viene la alimentación para el hogar y para la comunidad, que promueve y que impide el acceso a la alimentación, como se asegura la alimentación a nivel de hogar y la comunidad, las principales consecuencias de la inseguridad alimentaria, que hacen los hogares cuando no cuentan con dinero ni recursos para obtener alimentos, los cambios notados en la comunidad durante las últimas décadas sobre seguridad alimentaria, existencia de apoyo comunitario y gubernamental ante la falta recursos para alimentos, y conocimiento de la ley de soberanía y seguridad alimentaria, su concepto de soberanía y seguridad alimentaria. 
Para los actores sociales se hizo un total de 5 preguntas abiertas, estas preguntas fueron sobre: producción, migración, agua de consumo, plagas actuales, percepción de Seguridad Alimentaria, y propuestas para garantizarlo. Además se fueron entrevistados los Actores Sociales del municipio 11 en total: El Alcalde, el delegado del Ministerio Agropecuario (MAG), Delegado del Instituto Nacional Forestal (INAFOR), delegado del Instituto Nicaragüense de Tecnología Agropecuaria (INTA), Directora Municipal del Ministerio de Salud (MINSA), delegado del Ministerio de Educación (MINED), delegado de Fundación para la Autonomía y Desarrollo de la Costa Atlántica Nicaragüense (FADCANIC), Delegado de Ministerio de la Familia (MI-FAMILIA), representante de la Juventud Sandinista 19 de Julio, representante de la Iglesia Morava y el representante de la Iglesia Asambleas de Dios. A los actores se les hicieron 5 preguntas abiertas sobre la tenencia de la tierra, migración, historia productiva, plagas y monocultivos.

Para llevar a cabo el análisis de resultados se elaboró una matriz, para definir los resultados de los productores y mujeres amas de casa. Tablas para representar la situación planteada por los actores sociales.

\section{Breve caracterización de Kukra Hill}

La región central y costa caribe aportan casi el 73\% de la población en condición de pobreza general de todo el país. O sea que, de cada 10 pobres generales que tiene Nicaragua, aproximadamente siete provienen de alguna de estas dos regiones. Igualmente, estas dos regiones son las que mayor peso presentan en la pobreza extrema de la república, con la diferencia que, en este caso, el aporte es alrededor del $84 \%$ del total de pobres extremos. (INIDE 2014).

Por macro regiones, Managua exhibe las proporciones más bajas de población subsistiendo con 1.91 U\$ y 3.10 U\$ al día, solamente el $0.1 \%$ de su población tiene un consumo inferior a $1.91 \mathrm{U} \$$ al día y $3.2 \%$ tienen un consumo diario menor a 3.10 U\$. En el lado opuesto se ubican las regiones central y costa caribe, con $5.2 \%$ y $4.1 \%$ de su población que vive con menos de 1.91 U\$ al día y con $22.9 \%$ y $22.1 \%$ de su población que se mantiene con un consumo diario inferior a $3.10 \mathrm{US}$. (INIDE 2014).

Kukra Hill fue elevado a categoría de municipio en el año 1989, por la ley de división político-administrativo de Nicaragua. Antes de eso fue territorio de Bluefields. El territorio tiene una extensión de $1,262 \mathrm{~km} 2$. El Municipio de Kukra Hill está integrado en la Región Autónoma del Atlántico Sur (RAAS) y se encuentra a 30 kilómetros de la ciudad de Bluefields. y sus límites son: al Norte con el Municipio de El Tortuguero, al Sur con el Municipio de Bluefields, al Este con el Municipio de Laguna de Perlas y Mar Caribe y al Oeste con el Municipio de El Rama y una población de 9,559 habitantes. La mayoría de la población es de la etnia Mestiza, seguido de la etnia Creole, luego la etnia Miskitu, los Garífunas y por último los de la etnia Ulwas y Rama. (INIDE 2008).

Según la población entrevistada, hace más de 30 años cuando no existían las empresas que cultivan la Palma Africana (el Bambú y Cacao recientemente) en Kukra Hill se sembraban suficientes alimentos para la población. Después de la entrada de las empresas que cultivan la Palma Africana, la gente ya no se dedica a la producción de granos básicos sino a sembrar la palma africana, Bambú, Cacao, café robusta y Coco. Las autoridades estiman que el 75\% del municipio está cubierto de los monocultivos mencionados, y el 15\% están disponibles para sembrar otros cultivos.

El municipio no cuenta con un mercado local esto ha generado que la población no se dedique a la agricultura si no a la siembra de los monocultivos por lo que las empresas les compra su producción. Ellos aseguran que es un beneficio para ellos por lo que no tienen que buscar compradores e insumos por lo que las empresas les proporciona todo. 


\section{RESULTADOS Y DISCUSIÓN}

La alimentación es entendida como la comida, sin tomar en cuenta los valores nutricionales. Para las amas de casa la alimentación para el hogar viene de cosechar y comercializar la cosecha, de los campesinos que venden su cosecha, de comerciantes que llegan de la capital a vender productos alimenticios, de las pulperías en la comunidad y de la ayuda del gobierno. Los productores consideran que el alimento viene, del suelo, trabajo y el bolsillo, el trueque con otros productores, de los amigos, cuando les hace falta algo.

Ambos grupos opinan que hay que comprar lo que hace falta en la cocina. Hay que sembrar y guardar parte de la cosecha, y que es necesario tener un trabajo fijo para asegurar la alimentación en su hogar. Para garantizar el alimento en la comunidad, ambos grupos coinciden que cada familia tiene que pensar cómo resolver esto. La buena cosecha y su comercialización, tener trabajo y dinero promueve el acceso a la alimentación. Coinciden ambos grupos en que el cambio climático reflejado por la sequía o lluvia abundante, y las plagas como: Pájaros, ratas y zompopos provocan la pérdida de cosecha y por ende impide el acceso a la alimentación en el hogar y en la comunidad.

Las mujeres amas de casa mencionaron otras cosas: guardar parte de la cosecha en SILOS a fin de tener acceso a la alimentación, mencionaron como también: la estrategia de patio, como forma de garantizar el alimento en el hogar y la comunidad. Consideran que es importante economizar en el hogar, que debe haber más pulperías cerca, y una buena distribución del alimento para que llegue a las comunidades.

Los productores mencionaron, además, tener buen abono y materia prima, acceso a la tierra, y mejorar el rendimiento de la tierra, porque todo ello le impide el acceso a la alimentación tanto del hogar como en la comunidad, también consideran la necesidad de una estrategia de la agricultura familiar, al proponer que toda la familia debe trabajar para garantizar el alimento, y evitar malgastar la producción.

\section{Consecuencias de la inseguridad alimentaria}

El hambre es la principal consecuencia de la inseguridad alimentaria, y no permite que las personas lleven una vida activa y saludable, también se relaciona con algunas carencias nutricionales, ya que a la falta de recursos para accesar al alimento, permite el consumo de alimentos monótonos, ricos en carbohidratos y energéticos, pero pobre en valor nutricional, esto conlleva a la población a desarrollar enfermedades como es: la obesidad. También a la falta de alimento conlleva a perder peso excesivo y sufrir de desnutrición, especialmente los niños. Es importante enfocar la atención en la situación de salud, nutrición y desarrollo de la mujer y los adolescentes ya que una mujer desnutrida dará a luz a un niño desnutrido y con desventajas desde el nacimiento, que a su vez tendrá limitaciones para alcanzar un óptimo crecimiento y desarrollo, y conlleva en sí mismo el riesgo de engendrar generaciones con las mismas limitaciones. (INCAP 2004).

En la población entrevistada las consecuencias son graves, pues hay muchos niños desnutridos, pérdida de peso y hambre. También se presenta mucha violencia, robo asaltos y muertes por la falta de alimentos y recursos para su acceso.

Tabla $N^{\circ} 1$ : Principales consecuencias de la Inseguridad Alimentaria en el hogar y en la comunidad.

\begin{tabular}{|c|c|c|c|}
\hline $\mathbf{N}^{\circ}$ & Conceptos & $\begin{array}{c}\text { Mujeres Amas } \\
\text { de Casa Semi- } \\
\text { Urbano y Rural }\end{array}$ & $\begin{array}{c}\text { Productores } \\
\text { Semi-urbano y } \\
\text { Rural }\end{array}$ \\
\hline 6 & $\begin{array}{l}\text { ¿Cuáles son } \\
\text { las principales } \\
\text { consecuencias } \\
\text { en la } \\
\text { Inseguridad } \\
\text { Alimentaria en } \\
\text { el hogar y en } \\
\text { la comunidad? }\end{array}$ & $\begin{array}{l}\text { En el hogar: } \\
\text { - Familias enteras } \\
\text { desnutridas } \\
\text { - Niños } \\
\text { desnutridos } \\
\text { - Muerte } \\
\text { - Hambre }\end{array}$ & $\begin{array}{l}\text { En el Hogar: } \\
\text { - Enfermedad y } \\
\text { muerte } \\
\text { - Desnutrición } \\
\text { - Los niños se } \\
\text { ponen delgaditos } \\
\text { - Pérdida de peso }\end{array}$ \\
\hline
\end{tabular}




\section{En la comunidad: - Los niños \\ - Los niños y buscan comida algunas familias por otro lado se dedican a agarran lo que robar alimentos no es suyo \\ - Poca salud \\ - Los niños se enferman demasiado.}

Tabla $\mathbf{N}^{\circ}$ 2: Acciones que realizan los hogares, cuando no cuentan con suficientes recursos para comprar comida. Seguridad Alimentaria Nutricional, Kukra Hill-RACCS Nicaragua 2016

\begin{tabular}{|c|c|c|c|}
\hline $\mathbf{N}^{\circ}$ & Conceptos & $\begin{array}{l}\text { Mujeres Amas } \\
\text { de Casa Semi- } \\
\text { Urbano y Rural }\end{array}$ & $\begin{array}{c}\text { Productores } \\
\text { Semi-urbano y } \\
\text { Rural }\end{array}$ \\
\hline 7 & $\begin{array}{l}\text { ¿Qué hacen } \\
\text { los hogares } \\
\text { cuando no } \\
\text { cuentan con } \\
\text { recursos } \\
\text { suficientes } \\
\text { para adquirir } \\
\text { la cantidad de } \\
\text { alimentos que } \\
\text { necesitan? }\end{array}$ & $\begin{array}{l}\text { - Negociar los } \\
\text { productos que } \\
\text { tiene uno: } \\
\text { vender gallinas, } \\
\text { cerdo, huevo. } \\
\text { - La emigración } \\
\text { de los hombres } \\
\text { a otro lado para } \\
\text { obtener dinero y } \\
\text { comprar comida, } \\
\text { varios se van del } \\
\text { país. } \\
\text { - Fiar en venta. } \\
\text { - Reducir la } \\
\text { cantidad de las } \\
\text { comidas que } \\
\text { ingerimos a } \\
\text { diario. } \\
\text { - Trabajar doble, } \\
\text { economizar, } \\
\text { echar tortillas } \\
\text { además de tener } \\
\text { otro trabajo. }\end{array}$ & $\begin{array}{l}\text { - Me voy donde } \\
\text { familiares que } \\
\text { tienen comida, } \\
\text { y resuelvo el } \\
\text { problema. } \\
\text { - Se desintegra } \\
\text { la familia } \\
\text { emigrando } \\
\text { algunos para } \\
\text { otros lados en } \\
\text { búsqueda de } \\
\text { trabajo y mejor } \\
\text { salario para la } \\
\text { comida. } \\
\text { - Hacemos } \\
\text { prestamos en } \\
\text { los lugares que } \\
\text { prestan dinero. } \\
\text { - Reducimos } \\
\text { la ración de } \\
\text { comida en casa. } \\
\text { - Apoyamos a } \\
\text { otro productor } \\
\text { trabajándole la } \\
\text { tierra. } \\
\text { - Fía comida en } \\
\text { las pulperías. }\end{array}$ \\
\hline
\end{tabular}

Fuente: Entrevistas realizadas en Kukra Hill a amas de casa y productores. 2016

El cambio más grande y visible que tienen la humanidad y vivimos los efectos es el Cambio Climático. El cambio climático se suma al reto del rápido aumento de la demanda mundial de productos agrícolas -destinados a la alimentación, piensos y combustible- necesario para hacer frente al crecimiento de la población y el aumento en los niveles de ingresos.

"El calentamiento global tendrá profundas consecuencias sobre dónde y cómo se producen los alimentos, y llevará también a una reducción de las propiedades nutricionales de algunos cultivos, todo lo 
cual tiene implicaciones en las políticas de lucha contra el hambre y la pobreza y para el comercio mundial de alimentos, según afirman los expertos en un nuevo libro". (FAO 2015).

La entrevista a los productores y amas de casa refleja cambios drásticos que están sintiendo, entre esos cambios que perciben, son los efectos del calentamiento global, expresan que el verano se está extendiendo, el cultivo ha disminuido demasiado, precios de los alimentos han subido, hay menos trabajo, poco ingreso, salarios bajos, el difícil acceso a la tierra. Todo esto indica que el acceso a los alimentos es más difícil.

Tabla $N^{\circ}$ 3: Cambios que han visto a nivel personal y comunitario durante las últimas décadas. Seguridad Alimentaria Nutricional, Kukra Hill-RACCS Nicaragua 2016

\begin{tabular}{|c|c|c|c|}
\hline $\mathbf{N}^{\circ}$ & Conceptos & $\begin{array}{l}\text { Mujeres Amas } \\
\text { de Casa Semi- } \\
\text { Urbano y Rural }\end{array}$ & $\begin{array}{c}\text { Productores } \\
\text { Semi-urbano y } \\
\text { Rural }\end{array}$ \\
\hline 8 & $\begin{array}{l}\text { ¿Qué cambios } \\
\text { han visto o } \\
\text { sentido en } \\
\text { la Seguridad } \\
\text { Alimentaria } \\
\text { personal y } \\
\text { comunitaria } \\
\text { durante } \\
\text { las últimas } \\
\text { décadas? Por } \\
\text { qué? }\end{array}$ & $\begin{array}{l}\text { Personal: } \\
\text { - Comida está más } \\
\text { cara. } \\
\text { - El arroz y el } \\
\text { frijol están } \\
\text { carísimo. } \\
\text { - El salario es más } \\
\text { bajo } \\
\text { - Antes la } \\
\text { proporción de } \\
\text { alimentos estaba } \\
\text { mejor ahora está } \\
\text { más racionada. } \\
\text { - Veo todo igual. } \\
\text { En la comunidad: } \\
\text { - La empresa ha } \\
\text { traído cambios, } \\
\text { hay trabajo. } \\
\text { - Hay más } \\
\text { facilidad de } \\
\text { alimento. } \\
\text { - Antes se comía } \\
\text { un tiempo y } \\
\text { ahora hasta más } \\
\text { de tres. }\end{array}$ & $\begin{array}{l}\text { Personal: } \\
\text { - No he visto } \\
\text { cambio } \\
\text { - Cambios } \\
\text { climáticos } \\
\text { - El calor del } \\
\text { verano se } \\
\text { extiende más. } \\
\text { - El cultivo ha } \\
\text { disminuido } \\
\text { demasiado } \\
\text { - Vivimos igual } \\
\text { - Baja economía } \\
\text { - Alimentos con } \\
\text { precios más } \\
\text { altos } \\
\text { - Poco ingreso } \\
\text { En la comunidad: } \\
\text { - Alimento es } \\
\text { más difícil de } \\
\text { conseguir } \\
\text { - Acceso a la } \\
\text { tierra es difícil } \\
\text { - Mucha sequia } \\
\text { No hay cambio }\end{array}$ \\
\hline
\end{tabular}

$\begin{array}{ll}\text { - Manejamos } & \text { Hay más } \\ \text { animales } & \text { pulperías que } \\ \text { tenemos cuajada } & \text { abastecen } \\ \text { - Las mujeres } & \text { alimentos. } \\ \text { apoyamos a } & \\ \text { familias con } & \\ \text { alimentos para } & \\ \text { que no tengan } & \\ \text { que emigrar. } & \end{array}$

Fuente: Entrevistas realizadas en Kukra Hill a amas de casa y productores. 2016

La solidaridad permite alcanzar el desarrollo humano de las personas. Por eso, es fundamental que sea empleada en beneficios que puede ofrecer a una determinada causa. Su importancia radica en aplicarla cuando alguno de nuestros seres queridos, ya sean amigos o familiares, tengan algún problema en el que nuestra ayuda o compañía sean un aporte para mejorar en cierto modo la situación. Muchas veces se sostiene que la solidaridad es un buen modo de paliar situaciones dolorosas en las que el Estado demostró su ausencia.

Muchas veces es muy efectiva la organización popular. Esto sin embargo no es suficiente. Se debe garantizar la responsabilidad del gobierno local y los que administran los recursos actuar correctamente para evitar desastres o abandono de la población. Se debe monitorear la situación y no permitir que ocurran.

En la comunidad hay solidaridad entre las familias. Esto ha permitido que sobrevivan situaciones de migración masiva. Para las mujeres compartir alimentos, y tener acceso a los productos en las pulperías cuando los necesita, es importante. Sin embargo los productores refieren que la solidaridad entre ellos se manifiesta con el intercambio de semillas para que todos tengan de todas las semillas. Que cuando tiene necesidad su vecino le resuelve. Hay otros que consideran que no hay apoyo comunitario, que cada familia resuelve su propio problema (Ver tabla No.4). 
Tabla No 4: Apoyo comunitario cuando no tiene suficientes recursos para comprar alimentos. Seguridad Alimentaria Nutricional, Kukra Hill-RACCS Nicaragua 2016

\begin{tabular}{|c|c|c|c|}
\hline $\mathbf{N}^{\circ}$ & Conceptos & $\begin{array}{l}\text { Mujeres Amas } \\
\text { de Casa Semi- } \\
\text { Urbano y Rural }\end{array}$ & $\begin{array}{c}\text { Productores } \\
\text { Semi-urbano y } \\
\text { Rural }\end{array}$ \\
\hline 9 & $\begin{array}{l}\text { ¿Qué apoyo } \\
\text { comunitario } \\
\text { existe cuando } \\
\text { uno no cuenta } \\
\text { con recursos } \\
\text { suficientes } \\
\text { para adquirir } \\
\text { la cantidad de } \\
\text { alimentos que } \\
\text { necesitan? }\end{array}$ & $\begin{array}{l}\text { - No hay apoyo } \\
\text { por parte de la } \\
\text { comunidad, cada } \\
\text { quien busca por } \\
\text { su propio bien. } \\
\text { - Cada familia } \\
\text { se esfuerza } \\
\text { para llevar su } \\
\text { alimento al } \\
\text { hogar no he } \\
\text { sentido apoyo } \\
\text { alguno } \\
\text { - Realmente no } \\
\text { existe apoyo } \\
\text { alguno } \\
\text { - No he sentido } \\
\text { ningún apoyo } \\
\text { comunitario. } \\
\text { Tal vez un } \\
\text { poquito he visto } \\
\text { pero casi nada } \\
\text { para mí. } \\
\text { Si hay apoyo, } \\
\text { las personas que } \\
\text { tienen pulperías } \\
\text { nos dan } \\
\text { crédito cuando } \\
\text { necesitamos. } \\
\text { - No hay apoyo en } \\
\text { la comunidad. }\end{array}$ & $\begin{array}{l}\text { - } \text { Claro que existe } \\
\text { apoyo en la } \\
\text { comunidad } \\
\text { - Si existe } \\
\text { apoyo de otras } \\
\text { personas. } \\
\text { - Me voy donde el } \\
\text { vecino que me } \\
\text { resuelve. } \\
\text { - Hay intercambio } \\
\text { de semillas entre } \\
\text { productores para } \\
\text { que tengamos } \\
\text { de todas las } \\
\text { semillas. } \\
\text { - No he recibido } \\
\text { apoyo. } \\
\text { No hay apoyo. }\end{array}$ \\
\hline
\end{tabular}

Fuente: Entrevistas realizadas en Kukra Hill a amas de casa y productores. 2016

Los gobiernos necesitan tener una adecuada estrategia de desarrollo que cree condiciones para el crecimiento económico con igualdad. Los programas para alivio de la pobreza deben ser sostenibles. (FAO 2002)

El derecho a la seguridad alimentaria para toda la población se fundamenta en la Constitución Política de la República de Nicaragua, en el CAPITULO III sobre los DERECHOS SOCIALES, en el Art. 63, donde al Estado se reconoce la responsabilidad primaria para la materialización de ese derecho para su población y asume el compromiso de asegurar una población que goce de una buena alimentación y nutrición: "Es derecho de los nicaragüenses estar protegidos contra el hambre. El estado promoverá programas que aseguren una adecuada disponibilidad de alimentos y una distribución equitativa de los mismos".

Cualquier acción que realicen los gobiernos para mejorar los ingresos y reducir la pobreza, puede influir en la seguridad alimentaria; por ejemplo, aumentar la producción agrícola, especialmente por parte de familias rurales pobres; o garantizar precios justos para los productores y los consumidores; y hacer que los servicios sean accesibles a las personas.

"Nicaragua ha demostrado el más alto compromiso político para la lucha contra la pobreza, cuenta con un consejo interuniversitario de seguridad alimentaria que aglutina a 16 universidades, un Frente amplio parlamentario contra el Hambre reconocido a nivel internacional" (FAO 2015).

Tanto las amas de casa como los productores afirmaron necesitar el apoyo que el gobierno les ha facilitado a través de los programas productivo alimentario: "Hambre Cero, Usura Cero, semillas de frijoles y hortalizas. Además, existen otros programas como: Plan techo y una escuela en la comunidad. Sin embargo, valoraron que estos programas no a todas las personas les llega por igual (Ver tabla No.5).

Las mujeres amas de casa mencionan el programa hambre cero: entrega de gallinas, pelibuey, ganado, semillas de hortalizas, semillas de árboles frutales. Han dado letrinas, plan techo, casa para el pueblo. Algunas mujeres expresan que la ayuda llega a los mayores de edad y los que más necesitan. Otras opinan que ellas no reciben nada, por parte del gobierno.

Los productores manifiestan que son algunos productores que son beneficiados no todos. Otros dicen 
que nunca han recibido nada del gobierno. Coinciden tanto los productores como las mujeres amas de casa en el desconocimiento de la existencia de la ley sobre Soberanía y Seguridad Alimentaria. No han oído hablar sobre ella, no tiene conocimiento sobre dicha ley, por lo tanto, no saben su contenido.

Tabla $N^{\circ}$ 5: Apoyo del gobierno, cuando no tiene suficientes recursos para comprar comida. Seguridad Alimentaria Nutricional, Kukra Hill-RACCS Nicaragua 2016

\begin{tabular}{|c|c|c|c|}
\hline $\mathbf{N}^{\circ}$ & Conceptos & $\begin{array}{c}\text { Mujeres Amas } \\
\text { de Casa Semi- } \\
\text { Urbano y Rural }\end{array}$ & $\begin{array}{c}\text { Productores } \\
\text { Semi-urbano y } \\
\text { Rural }\end{array}$ \\
\hline 10 & $\begin{array}{l}\text { ¿Qué apoyo } \\
\text { gubernamental } \\
\text { existe cuando } \\
\text { uno no cuenta } \\
\text { con recursos } \\
\text { suficientes } \\
\text { para adquirir } \\
\text { la cantidad } \\
\text { y calidad de } \\
\text { alimentos que } \\
\text { necesitan? }\end{array}$ & $\begin{array}{l}\text { - Ha venido } \\
\text { ayuda, pero yo } \\
\text { no recibo nada. } \\
\text { - Entrega de } \\
\text { gallinas para que } \\
\text { algunas familias } \\
\text { salgan adelante. } \\
\text { - Han dado } \\
\text { pelibuey, } \\
\text { ganado, } \\
\text { hortalizas. } \\
\text { - Semillas para } \\
\text { árboles frutales. } \\
\text { - Letrinas } \\
\text { - Plan techo } \\
\text { - Casa para el } \\
\text { pueblo } \\
\text { - Existo pero a } \\
\text { mí no me ha } \\
\text { llegado. } \\
\text { El apoyo se da } \\
\text { a los mayores } \\
\text { de edad y los de } \\
\text { escasos recursos. } \\
\text { - No he recibido } \\
\text { ningún apoyo } \\
\text { alimentario } \\
\text { por parte del } \\
\text { gobierno. } \\
\text { - No he recibido } \\
\text { apoyo } \\
\text { gubernamental. }\end{array}$ & $\begin{array}{l}\text { - No he recibido } \\
\text { ningún apoyo } \\
\text { de parte del } \\
\text { gobierno } \\
\text { - Hambre cero } \\
\text { - Semilla de } \\
\text { frijoles } \\
\text { - Usura cero } \\
\text { - Techo para el } \\
\text { pueblo } \\
\text { - Escuelita para } \\
\text { los niños. } \\
\text { - Nunca he } \\
\text { recibido apoyo } \\
\text { del gobierno. } \\
\text { - Ningún apoyo } \\
\text { existe. } \\
\text { - No hemos } \\
\text { tenido apoyo del } \\
\text { gobierno. } \\
\text { El apoyo lo } \\
\text { reciben algunos } \\
\text { productores } \\
\text { otros no. } \\
\text { - Existe apoyo del } \\
\text { gobierno pero } \\
\text { no me abastece } \\
\text { a mí. } \\
\text { - Yo no cuento } \\
\text { con ellos. } \\
\text { - No recibo nada. } \\
\text { apo sé si hay } \\
\text { apoyo o no. }\end{array}$ \\
\hline
\end{tabular}

Fuente: Entrevistas realizadas en Kukra Hill a amas de casa y productores. 2016

\section{Tenencia de la Tierra y Uso}

La tenencia de la tierra es importante en las intervenciones de desarrollo rural que tratan de mejorar la dotación de activos de la población para que puedan disfrutar de medios de vida sostenibles. Los medios de subsistencia comprenden las capacidades, activos (incluidos los recursos tanto materiales como sociales) y las actividades correspondientes. Los derechos de propiedad sobre la tierra, junto con la mano de obra, forman el activo más común utilizado para producir alimentos destinados al consumo familiar, así como cultivos comerciales que permiten a la familia o a los individuos sufragar otras necesidades, por ejemplo, las relacionadas con la salud y la educación. FAO (2003). Se observan procesos de concentración impulsados por inversionistas centroamericanos con énfasis en la actividad ganadera, la palma africana y la caña de azúcar. También se dan presiones adicionales sobre la tierra por parte de capitales nacionales y extranjeros orientados a la expansión del turismo, la minería y las plantaciones forestales.

La venta de tierra es muy común en el municipio. No existe un mercado local, y los caminos son de difícil acceso. La población por necesidad vende sus tierras a las empresas trasnacionales y colonos que llegan a ofrecerles dinero y por necesidad ellos se deshacen de su patrimonio, emigrando hacia otro lugar. Y si permanecen con su tierra, se disponen a cultivar los productos que están demandando las grandes empresas, y les vende el producto. Los tipos de documentos que cuentan para respaldar legalmente su propiedad son: Escritura compra-venta, donación, posesión de derechos heredados y título de Reforma Agraria. Esto afecta directamente la disponibilidad de alimentos, porque en vez de producir alimentos para la población, producen productos que exportan la trasnacional. 


\section{Monocultivos en el municipio}

El efecto del monocultivo en la comunidad es: pérdida de biodiversidad, alteración del ciclo hidrológico, disminución de la producción de alimentos, degradación de suelos, conflictos comunales, disminución de fuentes de empleo, expulsión de la población rural y deterioro del paisaje turístico.

En todas partes del mundo los agricultores están siendo expulsados de sus tierras. En los campos que producían alimento para las comunidades ahora crecen cultivos para exportación. Las grandes empresas controlan cada vez más la tierra, las semillas, los mercados y las modalidades de distribución de alimentos, lo que no sólo perjudica a los agricultores, sino también a todos nosotros. (www.español.hesperian 2011).

Los monocultivos actualmente en el municipio son: la Palma Africana, seguida por el Cacao, Café Robusto, el Bambú y el Coco. De estos rubros, la Palma Africana es la que tiene la mayor parte de las tierras cultivadas, seguidas por el Cacao, el Café Robusta, el bambú y coco en la misma cantidad.

Los Actores sociales afirman que el sistema de producción hace treinta años era diferente, producían arroz, frijoles, maíz, caña de azúcar, frutales, alimentos que garantizaba la seguridad alimentaria. Los productores practicaban la rotación de cultivos. En las últimas décadas han venido adaptando otros sistemas de producción que enmarcan en la adaptación de nuevas técnicas agras productivas y de generación de semilla, llamadas semillas mejoradas. Los rubros que producen hoy es de mayor oferta económica y aceptación en el mercado, y los rubros que no son de interés mayor han ido desapareciendo del interés productivo. Los productos en su mayoría no son de autoconsumo, sino de generación de capital y capital extranjero: así vemos que el bambú, el aceite de palma, el cacao, el café robusto ocupan la producción, afectando la disponibilidad de alimento, y el arroz, frijoles, maíz inician la lista de la importación. Esto hace el acceso más difícil, porque sube el costo de los alimentos, junto a estos se suman los bajos salarios y la falta de trabajo.

Tabla $N^{\circ}$ 6: Rubros producidos durante las últimas III décadas. Seguridad Alimentaria Nutricional, Kukra Hill-RACCS Nicaragua

\begin{tabular}{llll}
\hline $\begin{array}{c}\text { Rubros que } \\
\text { producían } \\
\text { hace III } \\
\text { décadas atrás }\end{array}$ & $\begin{array}{c}\text { Rubros que } \\
\text { producen } \\
\text { actualmente }\end{array}$ & $\begin{array}{c}\text { Rubros } \\
\text { que se } \\
\text { importan }\end{array}$ & $\begin{array}{l}\text { Rubros que } \\
\text { se exportan }\end{array}$ \\
\hline Banano & Plátano & Arroz & $\begin{array}{l}\text { Aceite de } \\
\text { Palma }\end{array}$ \\
Caña de Azúcar & Banano & Frijol & Bambú \\
Hule & Yuca & Harina & Cacao \\
Maíz & Piña & Maíz & Café Robusto \\
Frijol & Coco & Tomate & Coco \\
Arroz & Chile & Chiltoma & Chile \\
Yuca & Pihbay & Cebolla & \\
Frutales & Mango & Repollo & \\
Musáceas & Naranja & Queso & \\
Madera & Guayaba & & \\
Quequisque & Aceite de palma & & \\
& Cacao & & \\
& Café Robusto & & \\
\hline
\end{tabular}

Fuente: Entrevistas realizadas en Kukra Hill a amas de casa y productores. 2016

Producto de las entrevistas realizadas a los delegados de los ministerios estatales (El Alcalde, el delegado del Ministerio Agropecuario (MAG), Delegado del Instituto Nacional Forestal (INAFOR), delegado del Instituto Nicaragüense de Tecnología Agropecuaria (INTA), Directora Municipal del Ministerio de Salud (MINSA), delegado del Ministerio de Educación (MINED), Delegado de Ministerio de la Familia (MI-FAMILIA) presentes en el municipio de Kukra Hill, expresan que existen una diversidad de plagas que inciden en la producción mermando la cantidad y la calidad. Se ha identificado que el rubro que más afectado por las plagas, es el frijol (Phaseolus vulgaris), también los otros rubros están afectados 
por las plagas pero de menor escala. Los pobladores de estas localidades expresan que ultimadamente hay plagas que nunca habían vistos, ellos suponen que es también producto del cambio climático.

Las grandes empresas logran controlar a las plagas con la aplicación de productos químicos realizando fumigaciones aéreas vía avión como es el caso de la Palma Africana. En caso de los pequeños productores para controlar las plagas, los combaten de manera cultural, realizan rondas, aplican sal y por también usan productos químicos, pero a menor escala.

Tabla $N^{\circ}$ 7: Principales plagas que afectan la producción. Seguridad Alimentaria Nutricional, Kukra Hill-RACCS Nicaragua

\begin{tabular}{|c|c|c|c|}
\hline & Plagas & Nombre científico & Plagas vs Rubros \\
\hline 1. & Chocoron & & $\begin{array}{l}\text { Se comen las } \\
\text { plantas de la Pal- } \\
\text { ma africana, } \\
\text { Frijol y Coco. }\end{array}$ \\
\hline 2. & Mariposa & $\begin{array}{l}\text { Leptinotarsa } \\
\text { decemlineata }\end{array}$ & Frijoles \\
\hline 3. & Mosca Blanca & Bemisia tabaci & $\begin{array}{l}\text { Afecta al maíz y } \\
\text { tomate. }\end{array}$ \\
\hline 4. & Babosa & Limax maximus & $\begin{array}{l}\text { Afecta al cultivo } \\
\text { de Frijol. }\end{array}$ \\
\hline 5. & La Concha & $\begin{array}{l}\text { Megalobulimus } \\
\text { ooblongus }\end{array}$ & Frijol \\
\hline 6. & Gallina Ciega & Phyllophaga spp & Plagas del suelo \\
\hline 7. & Coyogero & $\begin{array}{l}\text { Spodoptera } \\
\text { frugiperda }\end{array}$ & Maíz \\
\hline 8. & Zompopo & Atta spp & $\begin{array}{l}\text { Afecta a los } \\
\text { cítricos. }\end{array}$ \\
\hline 9. & Picudo & Sphenophorus spp & $\begin{array}{l}\text { Afecta a los } \\
\text { arboles de Coco y } \\
\text { Pihbay. }\end{array}$ \\
\hline 10. & $\begin{array}{l}\text { Gusano } \\
\text { Medidor }\end{array}$ & Mocis latipes & $\begin{array}{l}\text { Afecta al cultivo } \\
\text { de Tomate. }\end{array}$ \\
\hline
\end{tabular}

Fuente: Entrevistas realizadas en Kukra Hill a amas de casa y productores. 2016

\section{Migración}

En relación a la migración informan que los últimos 30 años ha habido mucha migración, especialmente del área rural. La migración de los autóctonos, ha aumentado durante los últimos años, y las principales razones son: el acceso a la tierra, búsqueda de trabajo y una remuneración justa. La mayor parte de los que migran su destino es fuera del país, principalmente a Costa Rica, seguido por Panamá, Estados Unidos, y los que embarcan en los grandes Cruceros trabajando. A lo interno de la Región Autónoma Costa Caribe Sur, migran a Bluefields, Laguna de Perlas y el Rama. La empresa The Kukra Development Corporation S.A. dedicada a la extracción de aceite de Palma Africana que está en el municipio, ha traído muchos migrantes de los departamentos como Chontales, Matagalpa, Boaco y a nivel interno de Bluefields y El Rama, sin embargo los salarios son bajos y no les alcanza para cubrir sus necesidades básicas de la familia, ni siquiera la comida, lo que motiva la migración.

El concepto de los actores sociales sobre seguridad alimentaria, es parcial e incompleto. Cada ministerio lo relaciona con su quehacer. El concepto dado por ellos se resume en: cantidad, inocuidad e higiene de alimentos mencionados por casi todos los actores, calidad nutricional mencionada por el MINSA y el INAFOR solamente. Como el concepto es limitado e incompleto, también las recomendaciones para alcanzar la seguridad alimentaria es limitada e incompleta. Evitar la contaminación, controlar los químicos utilizados en la producción y sembrar alimentos para abastecer al municipio. Es importante que cada uno de estos actores en el territorio tenga claro el significado de seguridad alimentaria nutricional, porque en esta medida definirán intervenciones adecuadas y oportunas que garanticen alcanzar el desarrollo sostenible. 
Tabla No 8: Concepto de Seguridad Alimentaria Nutricional según Actores Sociales. Seguridad Alimentaria Nutricional, Kukra Hill-RACCS Nicaragua

\begin{tabular}{|c|c|c|}
\hline $\begin{array}{c}\text { Actores sociales } \\
\text { de Kukra Hill }\end{array}$ & $\begin{array}{c}\text { Que es seguridad } \\
\text { alimentaria }\end{array}$ & $\begin{array}{c}\text { Recomendaciones } \\
\text { para alcanzarla }\end{array}$ \\
\hline ALCALDE & $\begin{array}{l}\text { Tener suficientes } \\
\text { alimentos sanos }\end{array}$ & $\begin{array}{l}\text { Capacitar a los } \\
\text { productores. Darles } \\
\text { semillas. }\end{array}$ \\
\hline INTA & $\begin{array}{l}\text { Tener hábito } \\
\text { de lavar las } \\
\text { frutas y evitar } \\
\text { enfermedades } \\
\text { y mantener los } \\
\text { patios limpios. }\end{array}$ & $\begin{array}{l}\text { Cambiar los métodos } \\
\text { de siembra y cosecha. } \\
\text { Utilizar otras } \\
\text { variedades de semillas } \\
\text { resistentes al cambio } \\
\text { climático. Sembrar } \\
\text { productos que se } \\
\text { puedan vender. }\end{array}$ \\
\hline INAFOR & $\begin{array}{l}\text { Consumir } \\
\text { alimentos de } \\
\text { manera sana } \\
\text { que no tenga } \\
\text { químico y que sea } \\
\text { nutritivo. }\end{array}$ & $\begin{array}{l}\text { No dar permiso } \\
\text { para extraer madera. } \\
\text { Realizar planes de } \\
\text { manejo y reponer } \\
\text { recursos. Capacitar a } \\
\text { productores. Promover } \\
\text { cultivo de alimentos } \\
\text { para abastecer al } \\
\text { municipio. }\end{array}$ \\
\hline MINED & $\begin{array}{l}\text { Tener suficiente } \\
\text { alimentos, } \\
\text { garantizar que a la } \\
\text { población no les } \\
\text { falte. }\end{array}$ & $\begin{array}{l}\text { Trabajar con } \\
\text { productores. Que } \\
\text { las autoridades no } \\
\text { emitan permisos de } \\
\text { concesión a la gente } \\
\text { para vender sus tierras. } \\
\text { Motivar a los alumnos } \\
\text { de 4to y 5to año } \\
\text { hacer investigaciones } \\
\text { agrícolas. Promover } \\
\text { carreras agro-técnicas. } \\
\text { Charlas de buenas } \\
\text { prácticas agrícolas. } \\
\text { Educar a los niños } \\
\text { hacia el cultivo, con } \\
\text { huertos escolares. }\end{array}$ \\
\hline MINSA & $\begin{array}{l}\text { Es tener } \\
\text { disponibilidad de } \\
\text { alimentos sanos y } \\
\text { nutritivos todo el } \\
\text { tiempo. }\end{array}$ & $\begin{array}{l}\text { Controlar y supervisar } \\
\text { los químicos } \\
\text { que ocupan en la } \\
\text { producción. }\end{array}$ \\
\hline $\begin{array}{l}\text { REP. J.S. } 19 \text { DE } \\
\text { JULIO }\end{array}$ & $\begin{array}{l}\text { Es el control } \\
\text { de la calidad de } \\
\text { los productos } \\
\text { agrícolas. }\end{array}$ & $\begin{array}{l}\text { Dar cursos de temas } \\
\text { agrícolas. Tomar en } \\
\text { cuenta la opinión de } \\
\text { los jóvenes. }\end{array}$ \\
\hline
\end{tabular}

PASTOR IGLE- Es producir Ser conscientes, pensar SIA MORAVA cultivos sin en el futuro. Hacer alteraciones. No buen recurso de la contaminar suelos. tierra.

PASTOR IGLE- Es tener suficiente Garantizar trabajo para SIA ASAM- comida para la la población

BLEA DE DIOS población Evitar contaminación.

Fuente: Entrevistas realizadas en Kukra Hill a amas de casa y productores. 2016

\section{CONCLUSIONES}

1. La disponibilidad de alimentos se ve afectado por la falta de tierra, el cambio climático, la proliferación de plagas, el verano prolongado, que afectan los cultivos y provocan perdida de cosecha.

2. La migración está muy activa en el territorio, los productores están vendiendo sus tierras a las trasnacionales y colones que llegan del pacifico y Norte del país, y emigran a otra zona del territorio o salen fuera de la misma, los que no venden sus tierras están cultivando los productos que las trasnacionales compran para elaboración de sus productos a exportar. Estas migraciones han contribuido al cierre de varias escuelas en el área rural, por falta de alumnos.

3. Las familias están en condiciones de subsistencia, con pocas posibilidades de almacenar alimentos que las proteja en tiempo de necesidad. Cuando las familias no cuentan con recursos para comprar alimentos, venden sus animales de patio, prendas de oro o plata, electrodomésticos, migración del padre, y por último la migración de la madre. También hay racionamiento de alimentos, y preparan alimentos que cubre con pocos gastos a toda la familia: sopa maggi, espagueti, indio viejo, guiso de pipián y papas.

4. La inseguridad alimentaria a nivel del hogar se evidencia por la falta de comida, la desnutrición, la alta morbilidad de los niños, y el hambre hace que niños y tercera edad piden limosna. En la comunidad se dan asaltos, muerte por robo de comida. Los actores sociales limitan el concepto de 
Seguridad Alimentaria Nutricional y la propuesta para garantizar la SAN, a la disponibilidad y la inocuidad de los alimentos.

5. Para hacerle frente al hambre cuando las familias no disponen de recursos, el apoyo comunitario es sentido entre los productores, a través del trueque, intercambio de semillas, regalías de otros productores de la cosecha, las amas de casa están viendo las pulperías como una solución al problema del hambre. El apoyo del gobierno es sentido por algunos productores y mujeres al ser beneficiados en proyectos como: Hambre Cero, Usura Cero, semilla de frijoles, hortalizas y frutales, plan techo, letrinas, y casa para el pueblo.

6. Los monocultivos están dominando el uso del suelo en el municipio: Palma Africana, Cacao, Café Robusta, Bambú y Chile, y están en manos de externos, algunas transnacionales. Se está importando: arroz, frijoles y maíz que son considerados como garantes de la seguridad alimentaria, pagando la población precios altos por estos rubros.

\section{RECOMENDACIONES}

1. Que el gobierno local defina un espacio de tierras para los alimentos básicos; arroz, frijoles y maíz, motivando a los productores y mujeres en el área rural a no venta de sus tierras, beneficiándolos con acceso a proyectos del gobierno, créditos, acceso a asesoría técnica y acceso a insumos.

2. Promover una articulación intersectorial y multinivel de discusión permanente, monitoreo y evaluación de la producción interna de productos alimenticios, precios de alimentos, importación de alimentos, generación de empleo, salarios justos a fin de garantizar la SAN en el territorio.

3. Que el ministerio de educación promociones los huertos escolares, investigaciones agrícolas, y carreras agrotécnicas, entre la población estudiantil y joven.

4. Evitar la contaminación de las aguas y suelos a través de control y la supervisión de químicos que ocupan las compañías en la producción.

\section{AGRADECIMIENTOS}

En primer lugar mi agradecimiento va hacia el Fondo de Investigaciones de la UNAN Managua, cuyo aporte me facilito todo el trabajo de campo y la finalización de este trabajo. Sin ese apoyo no hubiera sido posible. A los productores y mujeres del casco semi-urbano y rural del municipio que dieron parte de su tiempo para responder a la entrevista. Al gobierno local y los delegados del gobierno por su apoyo en la entrevista. Agradecimiento especial a la Lic. Elizabeth Ugarte, que apoyo con la entrevista a productores y mujeres. A la Lic. Lely Müller que apoyo en la entrevista con Actores Sociales.

\section{REFERENCIAS BIBLIOGRAFICAS}

Comité de Seguridad Alimentario Mundial CFS. (2012). En buenos términos con la terminología: Seguridad alimentaria, seguridad nutricional, seguridad alimentaria y nutrición, seguridad alimentario nutricional. Roma Italia

FAO. (2007). Guía de Seguridad Alimentaria y nutricional: Para el uso de Personal Agropecuario. Managua-Nicaragua

FAO. (2015). Evidencias de las implicaciones del cambio climático para la seguridad alimentaria y el comercio a nivel mundial Roma Italia

FAO, FIDA y PMA. 2015. El estado de la inseguridad alimentaria en el mundo: Cumplimiento de los objetivos internacionales para 2015 en relación con el hambre: balance de los desiguales procesos. Italia Roma

FAO (2016) El estado mundial de la agricultura y la alimentación: Cambio climático, agricultura y seguridad alimentaria Roma, Italia

Grupo de Agricultura y Alimentación de la Coordinadora de ONGD-E. (2012). SEGURIDAD ALIMENTARIA Y NUTRICIÓN EN EL MARCO 
POST-2015: Consulta electrónica sobre "El hambre y la seguridad alimentaria y nutricional”. Madrid-España

INCAP. (2004). La Seguridad Alimentaria Nutricional:

Un enfoque integral. Guatemala.

INIDE (2014). Encuesta mediciones del nivel de vida:

La pobreza en Nicaragua Managua-Nicaragua

Programa Mundial de Alimentos Nicaragua (2009).
Evaluación Rápida de Seguridad Alimentaria Nutricional. Managua - Nicaragua.

R. A. Manuel (2002). Lineamientos para seguridad alimentaria: Retos y perspectivas AntioquiaColombia

Stineke Oenema (2001). Profesional Asociada en Nutrición. La seguridad Alimentaria en los Hogares. FAO RLC 